\title{
Spatial Spillover Effect of Heterogeneous Environmental Regulation On Ecological Welfare Performance in China
}

guo bing nan ( $\sim 1107033980 @ q q . c o m$ )

Jiangsu University of Science and Technology

tang li

Jiangsu University of Science and Technology

jia ru

University of Leeds

lin $\mathbf{j i}$

Zhejiang University of Finance and Economics

Research Article

Keywords: heterogeneous environmental regulation, ecological welfare performance, spatial spillover

Posted Date: September 21st, 2021

DOl: https://doi.org/10.21203/rs.3.rs-698369/v1

License: (c) (i) This work is licensed under a Creative Commons Attribution 4.0 International License. Read Full License 


\title{
Spatial spillover effect of heterogeneous environmental regulation on
}

\author{
ecological welfare performance in China
}

\author{
GUO Bing-nan ${ }^{1}$, TANG $\mathrm{Li}^{1}$, JIA Ru², ${ }^{2}$ IN Ji ${ }^{3}$
}

1.School of Humanity \& Social Science, Jiangsu University of Science and Technology,

Zhenjiang Jiangsu 212003, China;

2.School of Sociology and Social Policy, University of Leeds, Leeds LS2 9JT, United Kingdom

3. School of Finance, Zhejiang University of Finance and Economics, Hangzhou 310018, China

Corresponding author: 200600002509@just.edu.cn (B. Guo)

E-mail addresses: 200600002509@just.edu.cn (B. Guo); 192090001@stu.just.edu.cn (L. Tang);evelynkimjia@163.com(R. Jia); linji1221@zufe.edu.cn: (J.Lin ) 3

Abstract: This paper constructs a theoretical model to deduce the mechanism of environmental regulation on ecological welfare performance, selects the panel data of 30 provinces in China from 2005 2019, uses the Super-SBM model to measure the ecological welfare performance of China, and the influence of heterogeneous environmental regulation on ecological welfare performance in China is empirically tested by spatial Durbin model.

The results show :(1) there are regional differences in the ecological welfare performance of different provinces in China, which illustrates an unbalanced spatial distribution;(2) there is significant positive spatial correlation between market incentive, command -control and voluntary participation environmental regulation and ecological welfare performance ;(3) The impact of different types of environmental regulations on the performance of ecological welfare in China is heterogeneous. Command-control and market incentive environmental regulations can improve the performance of ecological welfare, while voluntary participation environmental regulations have no significant impact on the performance of 
ecological welfare ;(4) From the perspective of spatial spillover effect, command-control

environmental regulation is not conducive to the ecological welfare performance of neighboring regions, while market incentive environmental regulation is conducive to the improvement of ecological welfare performance of adjacent areas. The spatial spillover effect of voluntary participation environmental regulation on ecological welfare performance in adjacent areas is not significant.

Keywords: heterogeneous environmental regulation; ecological welfare performance; spatial spillover consumption, which is derived from Daly's (2005) overview of the "full world" theory. He believes that human beings have entered a "full world" where natural capital is scarce, and then the economic growth at this time may not necessarily bring about the improvement of 
the welfare level. Relevant research on ecological welfare performance started relatively late but attracted much attention, etc. Existing literature can be roughly divided into three categories: The first type focuses on the connotation and measurement of ecological welfare performance (Zhu et al., 2014; Feng et al., 2016; Long et al., 2019); The second type of literature focuses on influencing factors affecting ecological welfare performance (Xiao et al., 2018; Du et al.; 2020).The research shows that technological development, greening level, urbanization are the main factors affecting the performance of ecological welfare; and the third literature studies the convergence and spatial effect of ecological welfare performance (Xu et al., 2019; Du et al., 2019; Fang et al., 2019; Xiao et al., 2020).

With the continuous improvement of national governance level and management system, the environmental regulation tools are constantly improved, and the domestic and foreign scholars on the economic impact of environmental regulation has carried on the related research. There are three most representative views: the first kind of view support "porter hypothesis", thinking appropriate environmental regulation will encourage enterprise innovation and improve the economic efficiency (Sinn,2008;Hoel,2010;Edwin et al., 2012; Zhang et al., 2012; Yang et al., 2012); The second type of view supports the "follow cost hypothesis" that environmental regulation increases enterprise production costs, occupies innovative investment and has negative impact (Lanoie et al., 2011; Hancevic et al., 2016; Xu et al.; 2017); The third view believes that the impact of environmental regulation on economic performance is uncertain, and different environmental regulation tools, time and space differences have on economic performance (Li et al., 2016; Cai et al., 2017).Most of the above literature studies focus on the relationship between environmental regulation and ecological efficiency, green economic efficiency and green development efficiency, while there are relatively few research on environmental regulation and ecological welfare performance, and regard environmental regulation as a whole, not considering the different influence of different environmental regulation tools.

1 To sum up, the existing literature still has the following shortcomings: first, it lacks the theoretical influence mechanism of environmental regulation on ecological welfare 
performance; second, the heterogeneity of environmental regulation is not considered. In fact, the impact of different environmental regulation tools may be different; Third, the lack of discussing the impact of environmental regulation on ecological welfare performance from a spatial perspective. Based on this, this paper makes the following expansion on the basis of the existing studies: (1) Theoretical systematically explains the action mechanism of environmental regulation on ecological welfare performance; (2) The heterogeneity of the impact of different environmental regulation tools on ecological welfare performance was investigated; (3) The spatial spillover effect of heterogeneous environmental regulation tools on ecological welfare performance was discussed.

\section{Theory Analysis and Hypothesis}

This article draws from Copeland and Taylor Thinking (Copeland and Taylor;1994), building the production model of the two departments, incorporating environmental regulation into the production function, deducing the analysis framework of industrial structure optimization and technological innovation as the basic path, and draw the research hypothesis that environmental regulation can promote the improvement performance of ecological welfare.

Suppose that the two production departments A and B respectively produce products a, b. a is a non-clean product, which will discharge e unit of pollutants during production. $\mathrm{b}$ is a clean product whose input elements are capital (K) and labor (L), and the C-D functions of the product $\mathrm{a}, \mathrm{b}$ is:

$$
\begin{aligned}
& F_{a}\left(K_{a}, L_{a}\right)=K_{a}^{\alpha} L_{a}^{\beta}, \quad \alpha+\beta=1 \\
& F_{b}\left(K_{b}, L_{b}\right)=K_{b}^{\delta} L_{b}^{\gamma}, \quad \delta+\gamma=1
\end{aligned}
$$

In the absence of environmental regulation, pollutant emission is in a fixed proportion to the output of product A. To reduce pollutant emission, another factor of a certain proportion should be input into the equation (1). The simultaneous production function equation of product $A$ is constructed as follows:

$$
a\left(K_{a}, L_{a}\right)=F\left((1-\theta) K_{a},(1-\theta) L_{b}\right)=(1-\theta) K_{a}^{\alpha} L_{a}^{\beta}
$$


112 intensity of environmental regulation $\theta$ pollutants a gradually reduce, the $\varphi(\theta)=$

$113(1-\theta)^{\frac{1}{\omega}}, \omega \in(0,1)$. According to the product b cost minimizing condition, the total cost

114 function of product $b$ is:

$$
c^{b}(r, w)=\left(\frac{r w}{\delta} w\right)\left(\frac{\delta r}{r w}\right)^{\gamma} F_{b}\left(K_{b}, L_{b}\right), \delta+\gamma=1
$$

Where, $r$ and $w$ are the factor prices of capital and labor respectively. Therefore, the

117 marginal cost of product $b$ is:

$$
m c^{F b}(r, w)=\frac{\delta^{-\delta}}{\gamma^{\gamma}} r^{\gamma} w^{\delta}
$$

119 Similarly, in the absence of environmental regulation, the marginal cost of producing

120 products a is: pollutant discharge, by constructing the first-order condition of the Lagrange equation, the pollutant discharge produced by A sector can be calculated as:

$$
m c^{F a}(r, w)=\frac{\beta^{-\beta}}{\alpha^{\alpha}} r^{\alpha} w^{\beta}
$$

$$
\lambda=\frac{e}{a}=\frac{\omega}{\tau}
$$

The profit functions of A and B are respectively:

The sewage charge is related to product pricing, and equation (3) and (8) are substituted into equation (9) to obtain:

$$
\begin{gathered}
\pi^{a}=a-r K_{a}-w L_{a}-\tau e \\
\pi^{b}=b-r K_{b}-w L_{b}
\end{gathered}
$$

$$
\pi^{a}=(1-\omega)(1-\theta) F_{a}\left(K_{a}, L_{a}\right)-r K_{a}-w L_{a}-\tau e
$$

Let $P^{F a}=(1-\omega)(1-\theta)$ and in a perfectly competitive market, the marginal cost of 133 enterprise profit maximization = product price, i.e., $m c^{F a}(r, w)=P^{F a}, m c^{F b}(r, w)=1$.

134 Substitute the maximization of enterprise profit into Equations (6) and (7), and the factor prices are respectively solved: 


$$
\begin{aligned}
& r=\left(\frac{\beta^{-\beta}}{\alpha^{\alpha}}\right)^{\frac{\gamma-1}{\alpha-\gamma}}\left(\frac{\delta^{-\delta}}{\gamma^{\gamma}}\right)^{\frac{1-\alpha}{\alpha-\gamma}}\left(P^{F a}\right)^{\frac{1-\gamma}{\alpha-\gamma}} \\
& w=\left(\frac{\beta^{-\beta}}{\alpha^{\alpha}}\right)^{\frac{-\gamma}{\gamma-\alpha}}\left(\frac{\delta^{-\delta}}{\gamma^{\gamma}}\right)^{\frac{\alpha}{\gamma-\alpha}}\left(P^{F a}\right)^{\frac{\gamma}{\gamma-\alpha}}
\end{aligned}
$$

According to Shepherd theorem, the total endowment of two factors of A country can be obtained from the demand of capital and labor for unit output of A and B sectors:

$$
\begin{aligned}
\bar{K} & =K_{a} F_{a}+K_{b} F_{b} \\
\bar{L} & =L_{a} F_{a}+L_{b} F_{b}
\end{aligned}
$$

Substituting Equations (1), (2), (12) and (13) into Equations (14) and (15), it can be concluded that the equilibrium output of $\mathrm{A}$ and $\mathrm{B}$ department is:

$a\left(P^{F a}, \bar{K}, \bar{L}\right)=\frac{\alpha\left(\frac{\beta^{-\beta}}{\alpha^{\alpha}}\right)^{\frac{-\gamma}{\gamma-\alpha}}\left(\frac{\delta^{-\delta}}{\gamma^{\gamma}}\right)^{\frac{\alpha}{\gamma-\alpha}}\left(P^{F a}\right)^{\frac{\gamma}{\gamma-\alpha}} \bar{L}-(1-\alpha)\left(\frac{\beta^{-\beta}}{\alpha^{\alpha}}\right)^{\frac{\gamma-1}{\alpha-\gamma}}\left(\frac{\delta^{-\delta}}{\gamma^{\gamma}}\right)^{\frac{1-\alpha}{\alpha-\gamma}}\left(P^{F a}\right)^{\frac{1-\gamma}{\alpha-\gamma}} \bar{K}}{\alpha-\gamma}$

$b\left(P^{F a}, \bar{K}, \bar{L}\right)=\frac{(1-\gamma)\left(\frac{\beta^{-\beta}}{\alpha^{\alpha}}\right)^{\frac{\gamma-1}{\alpha-\gamma}}\left(\frac{\delta^{-\delta}}{\gamma^{\gamma}}\right)^{\frac{1-\alpha}{\alpha-\gamma}}\left(P^{F a}\right)^{\frac{1-\gamma}{\alpha-\gamma}} \bar{L}-\gamma\left(\frac{\beta^{-\beta}}{\alpha^{\alpha}}\right)^{\frac{-\gamma}{\gamma-\alpha}}\left(\frac{\delta^{-\delta}}{\gamma^{\gamma}}\right)^{\frac{\alpha}{\gamma-\alpha}}\left(P^{F a}\right)^{\frac{\gamma}{\gamma-\alpha}} \bar{K}}{(1-\omega)(\alpha-\gamma)}$

To the $R=\left(\frac{\beta^{-\beta}}{\alpha^{\alpha}}\right)^{\frac{-\gamma}{\gamma-\alpha}}\left(\frac{\delta^{-\delta}}{\gamma^{\gamma}}\right)^{\frac{\alpha}{\gamma-\alpha}}, X=\left(\frac{\beta^{-\beta}}{\alpha^{\alpha}}\right)^{\frac{\gamma-1}{\alpha-\gamma}}\left(\frac{\delta^{-\delta}}{\gamma^{\gamma}}\right)^{\frac{1-\alpha}{\alpha-\gamma}}$, The effect of environmental

regulation on the equilibrium output of the two products is observed by taking the derivative of equation (16) and equation (17) with respect to pollution control cost $\tau$ respectively:

$\frac{\partial a\left(P^{F a}, \bar{K}, \bar{L}\right)}{\partial \tau}=\frac{\partial a\left(P^{F a}, \bar{K}, \bar{L}\right)}{\partial P^{F a}} \frac{\partial P^{F a}}{\partial \tau}=-\frac{\alpha \gamma R\left(P^{F a}\right)^{\frac{\alpha}{\gamma-\alpha}} \bar{L}+(1-\alpha)(1-\gamma) X\left(P^{F a}\right)^{\frac{1-\alpha}{\alpha-\gamma}} \bar{K}}{(\gamma-\alpha)^{2}} \frac{\partial P^{F a}}{\partial \tau}>0$

$$
\frac{\partial b\left(P^{F a}, \bar{K}, \bar{L}\right)}{\partial \tau}=\frac{\partial b\left(P^{F a}, \bar{K}, \bar{L}\right)}{\partial P^{F a}} \frac{\partial P^{F a}}{\partial \tau}=\frac{(1-\gamma)^{2} X\left(P^{F a}\right)^{\frac{1-\gamma}{\alpha-\gamma}} \bar{K}+\gamma^{2} R\left(P^{F a}\right)^{\frac{\alpha}{\gamma-\alpha}} \bar{L}}{(1-\omega)(1-\theta)} \frac{\partial P^{F a}}{\partial \tau}<0
$$

Since the $\alpha, \beta, \gamma, \delta, \omega 、 \theta \epsilon(0,1), P^{F a}=(1-\tau e)(1-\theta)$, the yield of non-clean product A will decrease when the environmental regulation intensity is high, i.e., the greater $\tau$. On the contrary, the output of cleaning product B will increase, and the industrial structure will be continuously optimized and upgraded. According to "Porter Hypothesis", the increase of environmental regulation intensity will increase the innovation input of enterprise production, promote enterprise innovation, and encourage the greening of 
159 level. Ecological welfare performance is the ratio of social welfare value to the consumption of ecological resources, which can be expressed as:

$$
E P=\frac{\sum w_{i} y_{i}}{\sum u_{v} e_{v}}
$$

Whereinto, $y_{i} 、 e_{v}$ are the pollution emission in the ith output and $v, w_{i}$ and $u_{v}$ are the proportion of their input factors, the molecular part of output is the sum of output a and output b, recorded as $Y(P, \tau, \bar{K}, \bar{L})$, and the denominator part is pollution output, denoised as $e^{a}(\bar{K}, \bar{L})$. Then equation (20) can be rewritten as:

$$
E P=\frac{Y(P, \tau, \bar{K}, \bar{L})}{e^{a}(\bar{K}, \bar{L})}=\frac{a\left(P^{F a}, \bar{K}, \bar{L}\right)+b\left(P^{F a}, \bar{K}, \bar{L}\right)}{\varphi^{a}(\theta)\left(P^{F a}, \bar{K}, \bar{L}\right)}
$$

Among them, $\frac{\partial a\left(P^{F a}, \bar{K}, \bar{L}\right)}{\partial \tau}>0 、 \frac{\partial b\left(P^{F a}, \bar{K}, \bar{L}\right)}{\partial \tau}<0$. Environmental regulation mainly shows the "structural" and "technological" effects. Among them, the technological effect is manifested as the improvement of technological level. On the one hand, the improvement of technological level can bring about the improvement of productivity, reduce the energy consumption per unit output, and thus reduce pollution emissions. On the other hand, the improvement of technology level can improve the environmental governance technology and environmental optimization. The structural effect is the upgrading of industrial structure, the reduction of polluting industries and the reduction of environmental pollution. The core connotation of ecological welfare performance includes environmental optimization, sustainable economic development, improvement of social welfare and other indicators.

179 helps to improve ecological welfare performance.

With the increase of the types of environmental regulatory tools, the heterogeneity of

181 different types of environmental regulatory tools has also attracted the attention of scholars.

182 Zhang J X et al. (2015) found in their research that market incentive environmental

183 regulations significantly improved the industrial green growth index, while command- 
185 W et al. (2016) found in their study that command-control and market incentive

186 environmental regulations have no significant impact on industrial operation performance.

187 Li X P et al. (2020) found in their study that market incentive environmental regulations

188 have the greatest promoting effect on carbon productivity, followed by command-control

189 environmental regulations. Wei W et al. (2020) found that both punitive environmental

190 regulation and incentive environmental regulation have significant promoting effects on

191 industrial environmental efficiency, and the effect of punitive environmental regulation

192 decreases in intensity while that of incentive environmental regulation increases in

193 intensity.

194 Therefore, this paper proposes theoretical hypothesis 2: there is heterogeneity in the

195 impact of different environmental regulation tools on ecological welfare performance.

196 4. Methodology and variables

4.1 Model

Based on the theoretical mechanism analysis and hypothesis, and by referring to the research of Li X P (2020), a spatial econometric model is constructed to empirically analyze

200 the spatial impact of heterogeneous environmental regulations on ecological welfare

201 performance. The model is as follows:

$$
E P=\alpha+\beta E R+\theta_{i} X+\rho W * e p+\varphi_{i} W * X+\eta_{i}+\delta_{t}+\mu_{i t}
$$

$$
\mu_{i t}=\lambda W * \mu_{i t}+v_{i t}
$$

In the formula (22), $\mathrm{W}$ represents the spatial weight matrix, EP represents the ecological welfare performance, ER represents different environmental regulation tools, $\mathrm{X}$

206 represents other control variables, $\eta_{i}, \delta_{t}$, and $\mu_{i t}$ represent individual effect, time effect 207 and random disturbance items respectively. When $\rho \neq 0, \varphi=0$ and $\lambda=0$, it is a spatial lag model.

208 When $\rho \neq 0, \varphi \neq 0$ and $\lambda=0$, it is a spatial Durbin model. When $\rho=0, \varphi=0$ and $\lambda \neq 0$, it is a spatial 209 error model.

$210 \quad 4.2$ Variable description

211 (1) Ecological welfare performance (EP). How to accurately measure the performance 212 of ecological welfare is the starting point of this analysis. Most of the existing literature uses 
213 data envelopment analysis method to construct the measurement index of ecological welfare

214 performance to measure the performance of ecological welfare. This paper uses the Super-

215 SBM method proposed by Tone (2001) to measure ecological welfare performance

216 according to its connotation and uses the indicator system of Long et al (2017) for reference.

217 The selected input indexes include energy consumption (per capita standard coal

218 consumption), land resources (per capita urban construction land area) and water resources

219 consumption (per capita water consumption). Output indicators include both desired output

220 and non-desired output. Desired output is expressed by the human development index,

221 which includes the level of health care (life expectancy), the level of education (average

222 years of schooling) and the level of economic development (per capita GDP). Undesired

223 outputs include wasting water (total industrial wasting water emissions per capita), waste

224 gas (industrial waste gas emissions per capita) and solid waste (industrial solid waste

225 emissions per capita).

226 (2) Environmental Regulation (ER). Reference Li X P(2020) research, environmental

227 regulation tools can be divided into command and control, market incentives and voluntarily

228 participated in three types, among them, the command control type (ER1) is mainly refers to

229 the government mandatory intervention activities of drainage measures, adopt various

230 provinces and cities "three simultaneity" environmental protection investment ratio as GDP

231 region; Market incentive type (ER2) refers to the influence of market forces on the

232 environmental behavior of the parties, which is measured by the ratio of resource tax to

233 local fiscal revenue. Voluntary participatory environmental regulation (ER3) refers to a non-

234 legal agreement that is expected to be established between the government, enterprises or

235 non-profit organizations with the purpose of improving environmental quality or resource

236 utilization, which is represented by the total number of environmental letters in each

237 province or city.

238 (3) Control variables. Technical level (Tc), which is represented by the number of

239 authorized patent applications and treated logarithmically. Industrial structure (Ind), which is

240 expressed as the proportion of the total output value of the tertiary industry in GDP. The 
241 degree of opening to the outside world (Open) is expressed as the proportion of total imports and

242 exports of each province in GDP. The level of economic development (Pgdp) is expressed by

243 GDP per capita and treated logarithmically. This paper takes the panel data of 30 provinces from

2442005 to 2019 as the research object (the data of Tibet is missing, so it is excluded, and Hong

245 Kong, Macao and Taiwan regions of China are not included), and the data are all from EPS

246 database.

\section{5. empirical analysis}

5.1 Descriptive Analysis

As can be seen from Table 1, the maximum value of ecological welfare performance is

2501.88 , and the minimum value is 0.26 . The large difference between the maximum value and

251 the minimum value indicates that there are inter-provincial differences in the ecological

252 welfare performance of provinces in China, showing the characteristics of unbalanced

253 spatial distribution. At the same time, the maximum and minimum values of different

254 environmental regulation tools in different provinces also have great differences, indicating

255 that there are regional differences in environmental regulation tools in different provinces.

Table 1 Descriptive statistics of the sample data

\begin{tabular}{cccccc}
\hline Variables & Definition & Means & Std. & Max & Min \\
\hline EP & Ecological welfare performance & 0.663 & 67.338 & 1.880 & 0.260 \\
ER1 & Market incentive-type & 2.645 & 73.223 & 21.470 & 0.001 \\
ER2 & Command control-type & 1.338 & 54.672 & 4.240 & 0.270 \\
ER3 & Voluntary participatory type & 0.087 & 0.011 & 0.063 & 0.113 \\
Open & Opening degree & 0.131 & 0.221 & 1.163 & 0.000 \\
Tc & Technological progress & 9.393 & 1.640 & 13.176 & 4.369 \\
Pgdp & Economic development level & 10.461 & 0.654 & 13.176 & 8.528 \\
Ind & Industrial structure & 0.435 & 0.099 & 0.835 & 0.000 \\
\hline
\end{tabular}


Figure 1 shows the geographical distribution of the mean value of ecological welfare performance of all Chinese provinces during the sample period. The darker the color, the higher the level of ecological welfare performance. There are four provinces whose ecological welfare performance value is greater than 1, namely Beijing, Tianjin, Hainan and Qinghai, accounting for about $13 \%$ of the whole country. From the perspective of geographical distribution, the regions with high ecological welfare performance are mainly concentrated in the eastern coastal areas, such as Jiangsu, Shanghai, Zhejiang, etc., which may be caused by the relatively high level of economic development, medical and health care level, education level and ecological and environmental protection level in the eastern coastal areas.

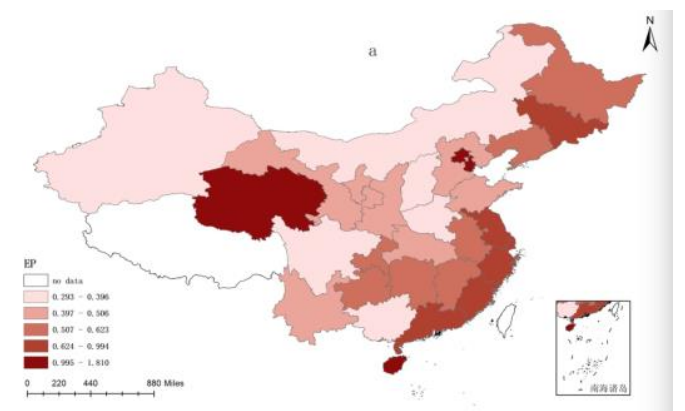

Figure 1 Spatial distribution of ecological welfare performance in various Chinese provinces

Fig. 2, Fig. 3 and Fig. 4 respectively show the spatial distribution of the annual mean value of environmental regulation intensity of command-control type, market incentive type and voluntary participation type. From the figure, we can intuitively see the differences in the geographical distribution of the three types of environmental regulations, and the implementation intensity of different types of environmental regulation tools in the same region is also different, which also indicates that there may be differences in the impact of 278 heterogeneous environmental regulations on ecological welfare performance. Specifically, the high value regions of command-control environmental regulation are mainly distributed

280 in Northwest China and Northeast China. The regions with high value of market incentive 281 environmental regulation are mainly distributed in the eastern and northwestern regions, 282 while the regions with low value are mainly concentrated in the western regions such as 

eastern regions, while the regions with low values are mainly concentrated in Xinjiang,

286 Qinghai, Shanxi and other northwestern regions.

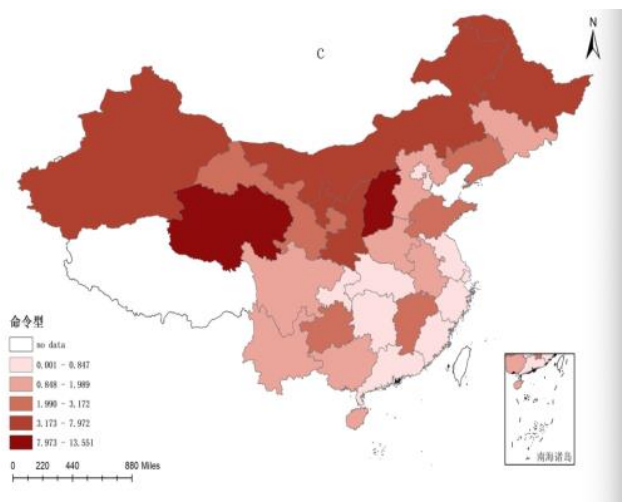

Figure 2. Spatial Distribution of Command Control the Market Environment Regulation

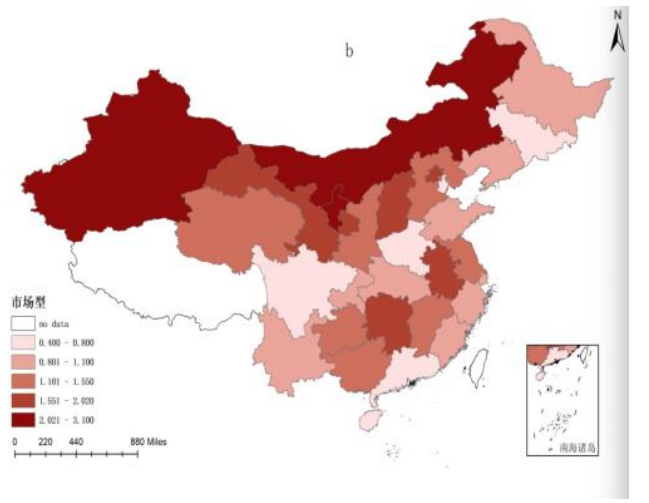

Figure 3 The Spatial Distribution of Incentive Environment Regulation

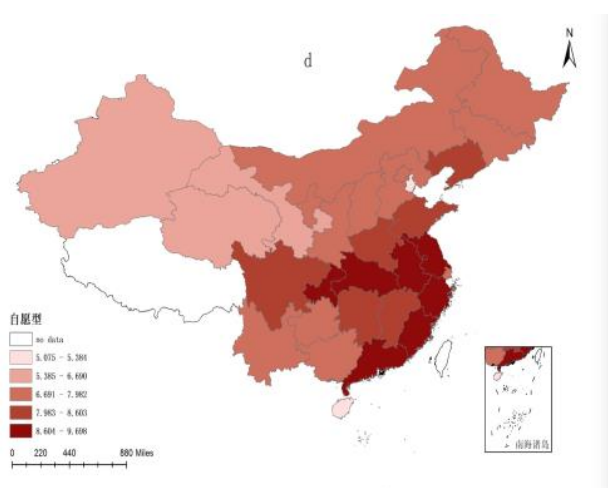

Figure 4. Spatial Distribution of voluntary participating Environment Regulation 5.3 Spatial correlation analysis In order to verify whether there is a spatial correlation between environmental regulations and ecological welfare performance in each province, the global Moran index was used to analyze the spatial correlation between market incentive, command-control, voluntary participation environmental regulations and ecological welfare performance, so as to judge whether there are spatial correlation characteristics. Table 2 shows the results of China's ecological welfare performance and the global Moran index test of the three environmental regulations under the economic-geographic nested weight matrix from 2005 to 2019. The results in Table 2 show that the Moran' I value of ecological welfare 
301 performance is greater than 0 , and the $\mathrm{P}$ values all pass the significance level test of $10 \%$.

302 The Moran' I value of market incentive, command control and voluntary participation

303 environmental regulation is greater than 0 , and the $\mathrm{P}$ value has passed the significance level

304 test of $10 \%$, which indicates that there is a significant positive spatial correlation between

305 the ecological welfare performance of different provinces and different types of

306 environmental regulation tools in China.

307

Table 2 Moran's I test results of heterogeneous environmental regulation and ecological 309 welfare performance

\begin{tabular}{|c|c|c|c|c|c|c|c|c|}
\hline \multirow[t]{2}{*}{ year } & \multicolumn{2}{|l|}{ EP } & \multicolumn{2}{|c|}{ Market incentive } & \multicolumn{2}{|c|}{ Command-control } & \multicolumn{2}{|c|}{$\begin{array}{c}\text { Voluntary } \\
\text { participation }\end{array}$} \\
\hline & Moran's I & $P$ & Moran's I & $P$ & Moran's I & $P$ & Moran's I & $P$ \\
\hline 2005 & $0.278^{* * *}$ & 2.332 & $0.383^{* * *}$ & 3.047 & $0.060^{* *}$ & 2.170 & $0.030^{* * *}$ & 2.781 \\
\hline 2006 & $0.280^{* * *}$ & 2.357 & $0.433^{* * *}$ & 3.308 & $0.089 * * *$ & 2.782 & $0.033^{* *}$ & 2.011 \\
\hline 2007 & $0.288^{* * *}$ & 2.395 & $0.457^{* * *}$ & 3.495 & $0.104^{* * *}$ & 3.125 & $0.011^{* * *}$ & 2.868 \\
\hline 2008 & $0.248^{* *}$ & 2.101 & $0.423^{* * *}$ & 3.328 & $0.095^{* * *}$ & 2.970 & $0.038^{* *}$ & 2.010 \\
\hline 2009 & $0.331^{* * *}$ & 2.679 & $0.354^{* * *}$ & 3.108 & $0.067^{* * *}$ & 2.480 & $0.033^{*}$ & 1.934 \\
\hline 2010 & $0.298^{* * *}$ & 2.438 & $0.536^{* * *}$ & 4.559 & $0.064^{* * *}$ & 2.407 & $0.037^{* *}$ & 2.004 \\
\hline 2011 & $0.317^{* * *}$ & 2.589 & $0.642^{* * *}$ & 5.306 & $0.091^{* * *}$ & 3.033 & $0.034^{*}$ & 1.812 \\
\hline 2012 & $0.306^{* * *}$ & 2.540 & $0.559^{* * *}$ & 4.436 & $0.084^{* * *}$ & 2.767 & $0.054^{* * *}$ & 2.308 \\
\hline 2013 & $0.307^{* * *}$ & 2.593 & $0.507^{* * *}$ & 3.941 & $0.085^{* * *}$ & 2.755 & $0.088^{* * *}$ & 3.174 \\
\hline 2014 & $0.321^{* * *}$ & 2.695 & $0.431^{* * *}$ & 3.450 & $0.069^{* * *}$ & 2.400 & $0.089^{* * *}$ & 3.244 \\
\hline 2015 & $0.276^{* * *}$ & 2.327 & $0.398^{* * *}$ & 3.234 & $0.047^{*}$ & 1.917 & $0.098^{* * *}$ & 3.448 \\
\hline 2016 & $0.269^{* *}$ & 2.236 & $0.335^{* * *}$ & 2.819 & $0.032^{*}$ & 1.770 & $0.091^{* * *}$ & 3.272 \\
\hline 2017 & $0.313^{* * *}$ & 2.569 & $0.346^{* * *}$ & 2.945 & $0.040^{*}$ & 1.775 & $0.088^{* * *}$ & 3.184 \\
\hline 2018 & $0.190^{* *}$ & 2.012 & $0.395^{* * *}$ & 3.286 & $0.055^{* *}$ & 2.129 & $0.091^{* * *}$ & 3.264 \\
\hline 2019 & $0.140^{*}$ & 1.878 & $0.385^{* * *}$ & 3.250 & $0.051^{* *}$ & 2.049 & $0.090^{* * *}$ & 3.262 \\
\hline
\end{tabular}

310 Note: ${ }^{*} \mathrm{P}<0.1,{ }^{* *} \mathrm{P}<0.05,{ }^{* * *} \mathrm{P}<0.001$ in the double tail test. 

In order to test the rationality of the model, the spatial lag model, the spatial error

314 model and the spatial Durbin model were regression respectively in this paper, and the 315 regression results are shown in Table 3. For the command-control type, market incentive 316 type and voluntary participation type, the spatial Durbin model has the largest degree of 317 fitting, the logarithmic likelihood function has the largest value, and the AIC and BIC have the 318 smallest value. Therefore, the spatial Durbin model is determined to be the optimal model. 319 It can be seen from the regression results that command-control, market incentive and voluntary participation environmental regulations all have a positive impact on China's 321 ecological welfare performance, which verifies hypothesis 1 that environmental regulations 322 are conducive to the improvement of ecological welfare performance. In Models (3), (6) and 323 (9), the estimated coefficient of $\rho$ is significantly positive, indicating that there is a positive spillover effect on ecological welfare performance among provinces, that is, there is mutual

325 influence on ecological welfare performance among neighboring provinces, showing the 326 characteristic of "one flourishing, one losing". From the perspective of the impact of different types of environmental regulations, different types of environmental regulations have 328 different impacts on ecological welfare performance. Proposition 2 can be verified that 329 heterogeneous environmental regulations have different impacts on ecological welfare 330 performance. Specifically, the regression coefficient of command-control environmental 331 regulations in Model (3) is significantly positive, with a coefficient of 0.004 , indicating that 332 an increase of 1 unit of command-control environmental regulations can promote an 333 increase of 0.004 unit of ecological welfare performance. In Model (6), the regression 334 coefficient of market incentive environmental regulation is significantly positive, with a 335 coefficient of 0.012 , indicating that increasing 1 unit of market incentive environmental 336 regulation can promote the improvement of ecological welfare performance by 0.012 units. 337 By contrast, the promoting effect of market incentive environmental regulation is greater than that of command-control environmental regulation. This may be because market 
339 incentive environmental regulation gives enterprises the free choice of technological

340 innovation and production and operation, which can reduce the execution cost. With the

341 continuous improvement of China's environmental monitoring system and legal system, the

342 effect of market incentive environmental regulation on the protection of China's

343 environment is increasingly strengthened. In Model (9), voluntary and participatory

344 environmental regulations have a positive but insignificant role in promoting ecological

345 welfare performance, which is consistent with the conclusion of Li X P(2020). This may be

346 because voluntary participatory environmental regulation depends on the public's conscious

347 awareness of environmental protection. However, there are still many problems in

348 voluntary participatory environmental regulation in China, such as the mismatch of public

349 conscious awareness of environmental protection and the low level of public participation,

350 which leads to the insignificant promotion effect of voluntary participatory environmental

351 regulation on ecological welfare performance.

352

353 Table 3 Test results of the influence of heterogeneous environmental regulation on 354 ecological welfare performance and space overflow effect in China

\begin{tabular}{|c|c|c|c|c|c|c|c|c|c|}
\hline \multirow[b]{2}{*}{ Variables } & \multicolumn{3}{|c|}{ Command-control (ER1) } & \multicolumn{3}{|c|}{ Market incentive (ER2) } & \multicolumn{3}{|c|}{ Voluntary participation (ER3) } \\
\hline & $\begin{array}{l}\text { SAR } \\
\text { (1) }\end{array}$ & $\begin{array}{l}\text { SEM } \\
\text { (2) }\end{array}$ & SDM（3） & $\begin{array}{l}\text { SAR } \\
(4)\end{array}$ & $\begin{array}{l}\text { SEM } \\
(5)\end{array}$ & $\begin{array}{l}\text { SDM } \\
(6)\end{array}$ & SAR (7) & SEM ( 8) & $\begin{array}{l}\text { SDM } \\
\text { (9) }\end{array}$ \\
\hline ER & $\begin{array}{c}0.004^{* *} \\
(2.22)\end{array}$ & $\begin{array}{c}0.005^{* * *} \\
(2.62)\end{array}$ & $\begin{array}{c}0.004^{* *} \\
(2.24)\end{array}$ & $\begin{array}{c}0.015^{* *} \\
(2.01)\end{array}$ & $\begin{array}{c}0.017^{* *} \\
(2.31)\end{array}$ & $\begin{array}{c}0.012^{* *} \\
(2.16)\end{array}$ & $\begin{array}{l}0.003 \\
(1.48)\end{array}$ & $\begin{array}{l}0.002 \\
(1.14)\end{array}$ & $\begin{array}{l}0.005 \\
(1.20)\end{array}$ \\
\hline Tc & $\begin{array}{l}0.012^{*} \\
(1.76)\end{array}$ & $\begin{array}{l}0.015^{*} \\
(1.86)\end{array}$ & $\begin{array}{c}0.371^{* * *} \\
(2.69)\end{array}$ & $\begin{array}{l}0.016^{*} \\
(1.79)\end{array}$ & $\begin{array}{c}0.021^{* *} \\
(1.88)\end{array}$ & $\begin{array}{c}0.404^{* * *} \\
(2.66)\end{array}$ & $\begin{array}{l}0.016^{*} \\
(1.89)\end{array}$ & $\begin{array}{l}0.018^{*} \\
(1.66)\end{array}$ & $\begin{array}{c}0.015^{* * *} \\
(2.88)\end{array}$ \\
\hline Ind & $\begin{array}{l}0.044 \\
(0.66)\end{array}$ & $\begin{array}{l}0.074 \\
(1.07)\end{array}$ & $\begin{array}{l}0.047 \\
(0.70)\end{array}$ & $\begin{array}{l}0.028 \\
(0.41)\end{array}$ & $\begin{array}{l}0.043 \\
(0.67)\end{array}$ & $\begin{array}{l}0.005 \\
(0.06)\end{array}$ & $\begin{array}{l}0.058 \\
(0.86)\end{array}$ & $\begin{array}{l}0.077 \\
(1.16)\end{array}$ & $\begin{array}{l}0.028 \\
(0.39)\end{array}$ \\
\hline Open & $\begin{array}{l}0.030 \\
(0.92)\end{array}$ & $\begin{array}{c}0.032^{* *} \\
(2.16)\end{array}$ & $\begin{array}{l}0.036^{*} \\
(1.96)\end{array}$ & $\begin{array}{l}0.049 * \\
(1.74)\end{array}$ & $\begin{array}{l}0.052^{*} \\
(1.73)\end{array}$ & $\begin{array}{l}0.040^{*} \\
(1.94)\end{array}$ & $\begin{array}{l}0.035 \\
(1.08)\end{array}$ & $\begin{array}{l}0.040 \\
(1.27)\end{array}$ & $\begin{array}{l}0.028 \\
(0.80)\end{array}$ \\
\hline Pgdp & -0.020 & -0.030 & $0.027^{* * *}$ & -0.019 & -0.02 & $0.018^{*}$ & -0.020 & -0.028 & -0.014 \\
\hline
\end{tabular}




\begin{tabular}{|c|c|c|c|c|c|c|c|c|c|}
\hline & $(-1.02)$ & $(-1.58)$ & (2.53) & $(-0.95)$ & $(-1.42)$ & (1.79) & $(-1.02)$ & $(-1.38)$ & $(-0.38)$ \\
\hline W ER & & & $\begin{array}{c}-0.421^{* *} \\
(-2.21)\end{array}$ & & & $\begin{array}{c}0.241^{* * *} \\
(2.96)\end{array}$ & & & $\begin{array}{l}0.181 \\
(0.35)\end{array}$ \\
\hline W Tc & & & $\begin{array}{c}0.442^{* * *} \\
(2.68)\end{array}$ & & & $\begin{array}{c}0.519^{* * *} \\
(3.07)\end{array}$ & & & $\begin{array}{c}0.512^{* * *} \\
(2.97)\end{array}$ \\
\hline W Ind & & & $\begin{array}{l}0.905 \\
(0.13)\end{array}$ & & & $\begin{array}{l}0.324 \\
(0.38)\end{array}$ & & & $\begin{array}{l}0.694 \\
(0.96)\end{array}$ \\
\hline W Open & & & $\begin{array}{l}-0.225 \\
(-0.61)\end{array}$ & & & $\begin{array}{l}-0.223 \\
(-0.57)\end{array}$ & & & $\begin{array}{l}-0.574 \\
(-0.15)\end{array}$ \\
\hline W Pgdp & & & $\begin{array}{c}-1.131^{* * *} \\
(-3.74)\end{array}$ & & & $\begin{array}{c}0.962^{* * *} \\
(3.05)\end{array}$ & & & $\begin{array}{c}1.059^{* * *} \\
(3.39)\end{array}$ \\
\hline$\rho / \lambda$ & $\begin{array}{c}0.079 * * \\
(1.99)\end{array}$ & $\begin{array}{l}0.155^{* *} \\
(2.27)\end{array}$ & $\begin{array}{c}0.199^{* * *} \\
(3.33)\end{array}$ & $\begin{array}{c}0.088^{* *} \\
(2.38)\end{array}$ & $\begin{array}{c}0.140^{* *} \\
(2.15)\end{array}$ & $\begin{array}{c}0.207^{* * *} \\
(2.99)\end{array}$ & $\begin{array}{l}0.062^{* *} \\
(2.10)\end{array}$ & $\begin{array}{l}0.102^{* *} \\
(1.97)\end{array}$ & $\begin{array}{c}0.112^{* * *} \\
(2.89)\end{array}$ \\
\hline $\mathrm{R} 2$ & 0.149 & 0.174 & 0.218 & 0.134 & 0.158 & 0.254 & 0.160 & 0.130 & 0.229 \\
\hline $\log \mathrm{L}$ & 591.152 & 592.821 & 628.496 & 590.7267 & 592.085 & 603.020 & 589.011 & 589.658 & 600.602 \\
\hline AIC & -968.304 & -971.642 & -1004.164 & -967.453 & -970.170 & -982.040 & -966.022 & -961.315 & -977.204 \\
\hline BIC & -939.539 & -942.877 & -954.853 & -938.689 & -941.405 & -932.729 & -935.257 & -936.551 & -967.893 \\
\hline $\mathrm{N}$ & 450 & 450 & 450 & 450 & 450 & 450 & 450 & 450 & 450 \\
\hline
\end{tabular}

355 Note: ${ }^{*} \mathrm{P}<0.1,{ }^{* *} \mathrm{P}<0.05$, ${ }^{* *} \mathrm{P}<0.001$, with $\mathrm{t}$ statistics in parentheses.

357 From the spatial spillover effect model (3), the region command-control type of the

358 strengthening of environmental regulation performance against adjacent regional ecological

359 welfare level of ascension, to increase 1 unit type command-control the intensity of

360 environmental regulation can reduce welfare performance 0.421 units in the adjacent

361 regions, this may be because in the management system of fiscal decentralization on our

362 region to take strict environmental regulation. Adjacent areas will become the transfer and

363 receiving places of polluting enterprises, resulting in increased pollution emissions in

364 adjacent areas and increased pressure on emission reduction, thus showing negative spatial 
spillover effect, which further confirms the research conclusion of Shen K R(2017). In Model

366 (6), the increase in the intensity of market incentive environmental regulations in this region is conducive to the improvement of the ecological welfare performance of neighboring regions, which is manifested as that the increase of 1 unit of market incentive environmental regulations in this region will improve the ecological welfare performance of neighboring regions by 0.241 unit. This may be because market incentive environmental regulations promote technological progress by promoting technological progress. The "learning effect" and "competition effect" promote the technological innovation and stimulate the "Porter effect" in the neighboring areas, and then produce positive spatial spillover effect on the ecological welfare performance in the neighboring areas. In Model (9), the spatial spillover effect of voluntary and participation environmental regulations on ecological welfare performance is not significant, which may be because voluntary and participation environmental regulations in China are still in the development stage and the public's environmental awareness is weak, so the spatial effect on ecological welfare performance is not significant.

\subsection{Robustness test}

The empirical analysis mainly reported the regression results of the economy geographical matrix. However, considering the spatial econometric analysis of spatial weight matrix of sensitivity, this paper further report based on adjacency matrix and geographic distance matrix in SDM model the heterogeneity of the spatial effect of environmental regulation on Chinese ecological benefits performance regression results, as shown in table 4. It can be seen from Table 4 that market incentive and command-control environmental regulations have a significant promoting effect on China's ecological welfare performance, and there is a significant spatial spillover effect on ecological welfare performance, but the size of the spillover effect is different, and the direction of the spillover effect is consistent with the above results. Therefore, the estimation results of the impacts of three different types of environmental regulations on China's ecological welfare performance and the spatial spillover effects are robust. 
Table 4. Robustness test results

\begin{tabular}{|c|c|c|c|c|c|c|}
\hline \multirow{2}{*}{ Var } & \multicolumn{3}{|c|}{ the adjacent matrix } & \multicolumn{3}{|c|}{ the geographical distance matrix } \\
\hline & ER1 & ER2 & ER3 & ER1 & ER2 & ER3 \\
\hline ER & $\begin{array}{l}0.002^{* *} \\
(2.27)\end{array}$ & $\begin{array}{l}0.012^{* *} \\
(1.99)\end{array}$ & $\begin{array}{l}0.005 \\
(1.08)\end{array}$ & $\begin{array}{c}0.005^{* * *} \\
(2.64)\end{array}$ & $\begin{array}{c}0.013^{* *} \\
(2.12)\end{array}$ & $\begin{array}{l}0.002 \\
(0.40)\end{array}$ \\
\hline Tc & $\begin{array}{l}0.002 \\
(0.19)\end{array}$ & $\begin{array}{l}0.004 \\
(0.28)\end{array}$ & $\begin{array}{l}0.001 \\
(0.09)\end{array}$ & $\begin{array}{l}0.011 \\
(0.96)\end{array}$ & $\begin{array}{l}0.017 \\
(1.37)\end{array}$ & $\begin{array}{l}0.013 \\
(1.09)\end{array}$ \\
\hline Ind & $\begin{array}{l}0.089 \\
(1.12)\end{array}$ & $\begin{array}{l}0.097 \\
(1.20)\end{array}$ & $\begin{array}{l}0.068 \\
(0.84)\end{array}$ & $\begin{array}{l}0.027 \\
(0.33)\end{array}$ & $\begin{array}{l}0.036 \\
(1.37)\end{array}$ & $\begin{array}{l}0.022 \\
(0.27)\end{array}$ \\
\hline Open & $\begin{array}{l}0.023 \\
(0.63)\end{array}$ & $\begin{array}{l}0.040 \\
(1.09)\end{array}$ & $\begin{array}{l}0.021 \\
(1.41)\end{array}$ & $\begin{array}{l}0.014 \\
(0.37)\end{array}$ & $\begin{array}{l}0.039 \\
(1.04)\end{array}$ & $\begin{array}{l}0.027 \\
(0.75)\end{array}$ \\
\hline Pgdp & $\begin{array}{c}0.081^{* *} \\
(2.27)\end{array}$ & $\begin{array}{l}0.038 \\
(1.09)\end{array}$ & $\begin{array}{l}0.052 \\
(1.41)\end{array}$ & $\begin{array}{l}0.010 \\
(0.33)\end{array}$ & $\begin{array}{l}0.021 \\
(0.67)\end{array}$ & $\begin{array}{l}0.022 \\
(0.69)\end{array}$ \\
\hline W ER & $\begin{array}{c}0.011^{* * *} \\
(3.03)\end{array}$ & $\begin{array}{c}0.043^{* * *} \\
(3.17)\end{array}$ & $\begin{array}{l}0.007 \\
(1.15)\end{array}$ & $\begin{array}{c}0.149^{* * *} \\
(2.44)\end{array}$ & $\begin{array}{c}0.073^{* * *} \\
(2.77)\end{array}$ & $\begin{array}{l}0.202 \\
(0.70)\end{array}$ \\
\hline W Tc & $\begin{array}{c}0.073^{* * *} \\
(3.19)\end{array}$ & $\begin{array}{c}0.079^{* * *} \\
(3.48)\end{array}$ & $\begin{array}{c}0.076^{* * *} \\
(3.29)\end{array}$ & $\begin{array}{l}0.044 \\
(0.07)\end{array}$ & $\begin{array}{l}0.756 \\
(0.39)\end{array}$ & $\begin{array}{l}0.120 \\
(0.58)\end{array}$ \\
\hline W Ind & $\begin{array}{l}0.220 \\
(1.17)\end{array}$ & $\begin{array}{l}0.213 \\
(1.17)\end{array}$ & $\begin{array}{l}0.142 \\
(1.07)\end{array}$ & $\begin{array}{l}0.226 \\
(0.20)\end{array}$ & $\begin{array}{l}0.157 \\
(1.33)\end{array}$ & $\begin{array}{l}0.022 \\
(0.27)\end{array}$ \\
\hline W Open & $\begin{array}{l}-0.042 \\
(-0.79)\end{array}$ & $\begin{array}{l}-0.042 \\
(-0.82)\end{array}$ & $\begin{array}{l}-0.019 \\
(-0.36)\end{array}$ & $\begin{array}{l}-0.437 \\
(-1.03)\end{array}$ & $\begin{array}{l}-0.413^{*} \\
(-1.87)\end{array}$ & $\begin{array}{l}-0.371^{*} \\
(-1.65)\end{array}$ \\
\hline W Pgdp & $\begin{array}{c}-0.159^{* * *} \\
(-3.87)\end{array}$ & $\begin{array}{c}0.133^{* * *} \\
(3.40)\end{array}$ & $\begin{array}{c}0.151^{* * *} \\
(3.86)\end{array}$ & $\begin{array}{l}-0.980 \\
(-0.31)\end{array}$ & $\begin{array}{l}0.102 \\
(0.03)\end{array}$ & $\begin{array}{l}0.701 \\
(0.22)\end{array}$ \\
\hline$\rho / \lambda$ & $\begin{array}{c}0.095^{* * *} \\
(2.55)\end{array}$ & $\begin{array}{c}0.077^{* * *} \\
(3.24)\end{array}$ & $\begin{array}{c}0.046^{* * *} \\
(2.74)\end{array}$ & $\begin{array}{c}0.087^{* * *} \\
(2.57)\end{array}$ & $\begin{array}{c}0.071^{* * *} \\
(2.70)\end{array}$ & $\begin{array}{c}0.085^{* *} \\
(2.48)\end{array}$ \\
\hline $\mathrm{R} 2$ & 0.206 & 0.212 & 0.114 & 0.181 & 0.087 & 0.077 \\
\hline
\end{tabular}




\begin{tabular}{|l|l|l|l|l|l|l|}
\hline $\log \mathrm{L}$ & 610.816 & 601.158 & 604.742 & 607.606 & 605.836 & 604.472 \\
\hline
\end{tabular}

$395 \quad$ Note: as Table 3.

\section{6. conclusions and recommendations}

This paper theoretically explains the action mechanism of environmental regulation on

398 ecological welfare performance. Based on the panel data of 30 provinces in $2005 \sim 2019$, the

399 spatial Durbin model constructed to test the spatial spillover effect of heterogeneous

400 environmental regulation on ecological welfare performance in China. The study found: (1)

401 there are regional differences in ecological welfare performance in Chinese provinces and

402 unbalanced regional spatial distribution. (2) Market incentive, command-control and

403 voluntary participation environmental regulation and ecological welfare performance has

404 significant positive spatial correlation. (3) The impact of different types of environmental

405 regulations on China's ecological welfare performance is heterogeneous. Command-control

406 and market incentive environmental regulations can improve China's ecological welfare

407 performance, but the promotion effect of market incentive environmental regulations is

408 stronger than that of command-control environmental regulations. The effect of voluntary

409 participatory environmental regulation is not significant. (4) From the perspective of space

410 spillover effect, the command-control environmental regulation is not conducive to the

411 improvement of ecological welfare performance in neighboring areas, while market

412 incentive environmental regulation is conducive to the improvement of ecological welfare

413 performance in neighboring areas, and voluntary participation environmental regulation has

414 no significant spatial spillover effect on ecological welfare performance in neighboring areas.

415 The above conclusions have important policy implications: (1) To establish a

416 collaborative mechanism for environmental regulation. In this paper, the study found that

417 environmental regulation and the ecological welfare performance were presented

418 significant spatial correlation, thus to build a targeted interest compensation mechanism, to

419 avoid the transfer of pollution across regions, build environment of local government

420 cooperative governance mechanism, a "zone spreading across the region is a common

421 environmental governance responsibility, break the local market segmentation, Eliminate 
local protectionism and "free rider" behavior, optimize resource allocation, and improve the performance of ecological welfare. (2) Choose appropriate environmental regulation tools according to local conditions. This study found that different environmental regulation tools have different impacts and spatial spillover effects on ecological welfare performance, and the impact of market incentive environmental regulation is stronger than that of commandtype environmental regulation. Therefore, local governments should continue to be encouraged to adopt market-oriented environmental regulation policies, such as investment in pollution control and resource tax, to promote technological innovation of enterprises through market means, also to improve ecological welfare performance. At the same time,

431 we should strengthen the positive impact of command-control environmental regulations,

432 prevent pollution transfer caused by command-control environmental regulations, and

433 reduce the negative impact of command-control environmental regulations on the ecological

434 welfare performance of neighboring areas. (3) Establish and improve the policy of voluntary

435 participation in environmental regulation. This study shows that the impact of voluntary

436 participatory environmental regulation is not significant. Therefore, to actively establish and 437 improve public participation in environmental management laws and regulations, establish 438 perfect and transparent government information publicity system, strengthen the enterprise 439 information disclosure, give full play to the supervision of the media initiative, intensify 440 propaganda and education, encourage the public to actively participate in environmental 441 protection, promote the voluntary participation environmental regulation of ecological 442 benefits are significant impact performance.

\section{Declarations}

446 1. Ethics approval and consent to participate

447 I certify that this manuscript is original and has not been published and will not 448 be submitted elsewhere for publication while being considered by Environmental 
450 the quantity of submissions and submitted to various journals or to one journal over

451 time. No data have been fabricated or manipulated (including images) to support your

452 conclusions. No data, text, or theories by others are presented as if they were our own.

453 The submission has been received explicitly from all co-authors. And authors whose

454 names appear on the submission have contributed sufficiently to the scientific work

455 and therefore share collective responsibility and accountability for the results.

456 This article does not contain any studies with human participants or animals

457 performed by any of the authors.

458 Informed consent was obtained from all individual participants included in the 459 study.

$460 \quad$ Conflict of Interest: The authors declare that they have no conflict of interest.

461 2. Consent for publication

$462 \quad$ Not applicable.

463 All data generated or analysed during this study are included in this published article.

464 3.Competing interests

465 The authors declare that they have no competing interests.

$466 \quad$ 4.Funding

$467 \quad$ Not applicable.

468 5.Authors' contributions

469 Guo Bingnan checked the rationality of the article. Tang li analyzed and interpreted 470 the data and established the model, and was a major contributor in writing the manuscript. Jia 471 ru proofread the article. Lin Ji provided reliable advice for writing the article. All 472 authors read and approved the final manuscript.

\section{References}

475 Cai, W.G., Zhou, X.L.,2017. Dual effect of Chinese environmental regulation on green total 476 factor productivity. Economist. (9):27-35. 
478 Journal of Economics. 109(3):755-787.

479 Daly H.E.,2005. Economics in a full world. Scientific American. (3),100-107.

480 Du, H.B., Huang, L.J., Zhang, C., He, J. J.,2019. Research on the regional differences

481 decomposition and convergence mechanism of ecological well-Being performance.

482 Ecological Economy. 29(03):1-10.

483 Edwin, Van, Der, et al.,2021. Imperfect environmental policy and polluting emissions: the

484 green paradox and beyond. International Review of Environmental and Resource Economics. 485 6(2):153-194.

486 Fang, S.J., Xiao Q.,2019. Research on regional ecological well-being performance and spatial 487 effect in China. China population, resources and environment. 29(3):1 - 10.

488 Feng, J. F., Yuan, J. H., 2016. On Chinese regional ecological well-being performance and its 489 influence factors. China Science and Technology Forum. (03):100-105.

490 Hancevic I P.,2016. Environmental regulation and productivity: the case of electricity 491 generation under the CAAA-1990. Energy economics. 60: 131-143.

492 Hoel M.,2010. Is there a green paradox? CESifo Working Paper Series. 100(11):1999-2030.

493 Lanoie P, Laurent-lucchetti J, Johnstone N, et al.,2011. Environmental policy, innovation and 494 performance: new insights on the Porter Hypothesis. Journal of economics \& management 495 strategy. 20(3):803-842.

496 Li B, Wu S S.,2016. Effects of local and civil environmental regulation on green total factor 497 productivity in China: a spatial Durbin econometric analysis. Journal of Cleaner Production. $498 \quad 153: 342-353$.

499 Li, C.Y., Zhang, S.Q., Zhang, W. et al., 2019. Measurement and influencing factors of inter500 provincial ecological well-being performance in China. Scientia Geographica Sinica. 39(12): $501 \quad 1875-1883$.

502 Li, X. P., Yu, D. S., Yu, J. J.,2020. Spatial spillover effect heterogeneous environmental 503 regulations on carbon productivity-spatial Durbin model. China Soft Science. (04):82-96. 
505 cities based on two-stage super-efficiency network SBM Model. China population, resources and environment. 29(7): 1 - 10.

507 Sinn H.,2008. Public policies against global warming: a supply side approach. International 508 Tax Public Finance. (4):360-394.

509 Tone, K.,2001. A slacks-based measure of efficiency in data envelopment analysis. European $510 \quad$ Journal of Operational Research. (3):498-509.

511 Wei, W.,2020. Heterogeneous environmental regulation, clean technology structure and 512 improvement of regional industrial environmental efficiency. Technology and Economy. 513 39(06):119-130+140.

514 Xiao, L.M., Xiao, Q.L.,2021. Study on the differentiation and spatial convergence of urban 515 ecological welfare performance patterns in the Yellow River Basin. Soft Science. 35(02):4651653.

517 Xu, Y.D., Qi, P., Tong, L.F.,2017. Spatial-temporal differentiation of Chinese provincial 518 ecological well-being performance. Regional Economic Review. (04):123-131.

519 Xu, Y. K.,2017. Re-evaluate the impact of environmental regulation on enterprise 520 productivity and its mechanism. Finance \& Trade Economics.38(6):147-161.

521 Yang, C. H., Tseng, Y. H., Chen, C. P.,2012. Environmental regulations, induced R\&D, and 522 productivity: evidence from Taiwan's manufacturing industries. Resource \& energy 523 economics.34(4):514-532.

524 Yu, W., Chen, Q., Chen, H.,2016. Analysis of the impact of different environmental policy 525 instruments on technology innovation: evidence from China's 30 provinces' panel data from 526 2004-2011. Management Review. 28(1):53-61.

527 Zhang, C. H., Liu, H. Y., Bressers, H. T. A., et al.,2011. Productivity growth and environmental 528 regulations-accounting for undesirable outputs: analysis of China's thirty provincial regions 529 using the Malmquist-Luenberger Index. Ecological economics.70(12):2369-2379.

530 Zhang, J.X., Cai, N., Yang, C.,2015. Impact of environmental regulation on green growth index 531 of industry in China. China population, resources and environment. 25(1):24-31. 
532 Zhu, D. J., Zhang, S.,2014. Research on ecological wellbeing performance and its relationship

533 with economic growth. China Population, Resources and Environment. 24(09):59-67. 